\title{
Stammzellen und ihre Bedeutung in der Dermatologie
}

\section{Epidermal Stem Cells and their Importance in Dermatology}

\section{Autor}

Institute

\section{C. Zouboulis ${ }^{1,2}$}

Klinik für Dermatologie, Venerologie und Allergologie/Immunologisches Zentrum, Städtisches Klinikum Dessau, Dessau-Roßlau

2 Laboratorium für Biogerontologie, Dermatopharmakologie und Dermato-Endokrinologie, Institut für Klinische Pharmakologie und Toxikologie, Charité Universitätsmedizin Berlin

\section{Bibliografie}

Dol $10.1055 / \mathrm{s}-0028-1119597$

Akt Dermatol 2009; 35:

120-128 @ Georg Thieme

Verlag KG Stuttgart · New York ISSN 0340-2541

Korrespondenzadresse

Prof. Dr. Christos C. Zouboulis Klinik für Dermatologie,

Venerologie und Allergologie/ Immunologisches Zentrum Städtisches Klinikum Dessau Auenweg 38 06847 Dessau-Roßlau christos.zouboulis@ klinikum-dessau.de

\section{Zusammenfassung \\ $\nabla$}

Die Hauthomeostase wird von epidermalen Stammzellen gesichert, welche sich selbsterneuern und Tochterzellen generieren, die eine terminale Differenzierung ausweisen. Mehrere spezialisierte Hautstammzellenpopulationen sind bereits nachgewiesen worden. Genetische Markierungsstudien wiesen multipotente Stammzellen im Haarfollikel auf, welche die Regeneration der Haarfollikel unterstützen, aber für den Aufbau der interfollikulären Epidermis nicht verantwortlich sind. Die Letztere besitzt eine eigene Stammzellpopulation. Bei Gefährdung der Hautintegrität, z.B. nach Verbrennung, übernehmen jedoch Haarfollikelstammzellen die epidermale Regeneration. Andererseits sind die Zellen der Wulstregion, die ersten adulten Hautstammzellen, die identifiziert wurden, fähig, Haarfollikel, interfol-

\section{Definition der Stammzellen} $\nabla$

Als Stammzellen werden Körperzellen bezeichnet, die sich in verschiedene Zelltypen oder Gewebe ausdifferenzieren können. Je nach Art der Stammzelle und ihrer Beeinflussung haben sie das Potenzial, sich in jegliches Gewebe (embryonale Stammzellen) oder in bestimmte festgelegte Gewebetypen (postembryonale Stammzellen) zu entwickeln.

\section{Embryonale Stammzellen}

$\nabla$

Zygoten (befruchtete Eizellen) und Zellen junger Embryos nach Befruchtung der Eizelle und bis zum Morulastadium (8-Zellstadium) sind totipotente Zellen, das heißt Zellen, die auch zu Gameten (Zellen der Keimbahn) ausdifferenzieren können und ontogenetisches Potenzial besitzen [1]. Embryonale Stammzellen, die im Entwick- likuläre Epidermis und Talgdrüsen zu bilden. Außerdem können sich aus Zellen der Wulstregion - mindestens in den Haarfollikeln der Maus - auch nichtepitheliale Zellen entwickeln, welche auf einen abstammungsunabhängigen, pluripotenten Charakter der Wulstregion hinweisen. Multipotente Zellen (hautabstammende Progenitorzellen) sind in der menschlichen Dermis vorhanden. Dermale Stammzellen stellen 0,3\% der Vorhautfibroblasten dar. Progenitorzellen existieren auch in den Talgdrüsen und sind in der Lage, sowohl Talgdrüsenzellen als auch Zellen der interfollikulären Epidermis zu generieren. Die unterschiedliche Selbsterneuerung und Abstammungsdifferenzierung der Stammzellen der Haut machen diese Zellen für die regenerative Medizin, die Gewebeersatzforschung, die Gentherapie und die zellbasierte Therapie mit autologen adulten Stammzellen attraktiv.

lungsstadium der Blastozyste aus der inneren Zellmasse (auch Embryoblast genannt) gewonnen werden, betrachtet man als pluripotent, das heißt, dass sie die Fähigkeit besitzen, sich in Zellen der drei Keimblätter, nämlich zum Entoderm, Ektoderm und Mesoderm, zu differenzieren [2]. Embryonale Stammzellen haben auch die Fähigkeit zur Selbsterneuerung. Auf diese Art sind sie in der Lage, durch zahlreiche Zyklen der Zellteilung zu gehen, während sie den undifferenzierten Status behaupten [3]. Über das jeweilige Schicksal der Zellen entscheidet dabei vor allem das biologische Milieu, in dem sie sich befinden. Embryonale Stammzellen wurden erstmals 1981 aus der Maus isoliert [4]. In vitro erfahren sie eine spontane Differenzierung, welche unterbunden werden kann, um die Selbsterneuerung der Zellen zu fördern. Der Einsatz differenzierungshemmender Faktoren führt zu unbegrenzter Vermehrung der embryonalen Stammzellen [5], was unter anderem auch mit der hohen Aktivität des 
Enzyms zusammenhängt. Damit unterscheiden sich embryonale Stammzellen von anderen, sogenannten primären Körperzellen, die ihre Teilungsaktivität in der Kulturschale meist nach kurzer Zeit einstellen (replikative Seneszenz). Embryonale Stammzellen der Maus können in Präimplantationsembryonen wieder eingeführt und nach deren Transfer in scheinschwangere Tiere am Aufbau aller fötalen Gewebe beteiligt werden. Dies kann für die zielgerichtete Ausschaltung bestimmter Gene in Mäusen benutzt werden. Knock-out-Mäuse lassen sich unter Nutzung von embryonalen Stammzellen deutlich schneller produzieren als mit herkömmlichen Techniken.

Weiterhin können embryonale Stammzellen in vitro zu verschiedensten Zelltypen ausdifferenziert werden. Dieses Gebiet wurde insbesondere ab 1998 mit der erstmaligen Etablierung von humanen embryonalen Stammzellen durch Thomson belebt [2]. Humane embryonale Stammzellen werden aus sogenannten überzähligen Embryonen gewonnen, die durch In-vitro-Fertilisation entstanden sind, nicht mehr für Fortpflanzungszwecke benötigt werden und daher tiefgefroren gelagert werden. Das Hauptinteresse der Forschung an humanen embryonalen Stammzellen gilt der Differenzierung in spezialisierte Zellen, um diese für mögliche Zellersatztherapien verfügbar zu machen. Neben der Gewinnung von embryonalen Stammzellen aus In-vitro-Fertilisation-Blastozysten ist auch eine Gewinnung durch Klonen von Embryonen möglich. Grundlage für diese Möglichkeit war das erste erfolgreiche Klonen eines Säugetiers im Jahr 1997, des Schafs „Dolly“ [6]. Unter Nutzung dieser Technik kann durch Übertragung des Zellkerns aus einer Körperzelle in eine unbefruchtete Eizelle ein früher Embryo entstehen, aus dem embryonale Stammzellen angelegt werden können. Die Methode führt zu embryonalen Stammzellen, die mit den embryonalen Stammzellen des Spenders genetisch identisch sind. Im Juni 2007 gelang Mitalipov u. Mitarb. [7], Primaten, nämlich Rhesusaffen, zu klonen und aus den erhaltenen Embryonen zwei Linien embryonaler Stammzellen zu gewinnen, wobei dabei das gleiche Verfahren wie bei dem Schaf „Dolly“ angewandt wurde.

\section{Ethische Debatte und Gesetzeslage in der Bundesrepublik Deutschland \\ $\nabla$}

Die Art der Gewinnung menschlicher embryonaler Stammzellen nach In-vitro-Fertilisation führte zu einer andauernden ethischen Debatte in der Bundesrepublik Deutschland. Die Verwendung von menschlichen embryonalen Stammzellen in der Forschung und Medizin wird von einem Teil der Gesellschaft abgelehnt, da zu ihrer Gewinnung die Zerstörung von frühen menschlichen Embryonen erforderlich ist („verbrauchende“ Embryonenforschung). Grundsätzlich geht es bei der Diskussion vor allem um die Frage, ob der frühe Embryo als menschliches Wesen unter den Würdeschutz des Grundgesetzes fällt und damit sein Leben keinerlei Abwägungen unterliegen darf.

Nach dem Embryonenschutzgesetz ist es in der Bundesrepublik Deutschland verboten, menschliche Embryonen einschl. Blastozysten, die als Quelle für embryonale Stammzellen dienen, für Forschungszwecke herzustellen, zu klonen oder zu zerstören. Die Forschung an importierten embryonalen Stammzellen ist jedoch unter Auflagen möglich und wurde zunächst durch das Stammzellgesetz vom Juli 2002 geregelt. Dieses Gesetz enthielt die Regelung, dass nur embryonale Stammzellen nach Deutschland importiert werden durften, die vor dem 1. Januar 2002 gewonnen worden waren (Stichtagsregelung). Am 11. April 2008 beschloss der Deutsche Bundestag einen neuen Stichtag, sodass nun Stammzellen importiert werden dürfen, die vor dem 1. Mai 2007 gewonnen wurden.

\section{Postembryonale Stammzellen \\ $\nabla$}

Die Gruppe der postembryonalen Stammzellen umfasst die Stammzellen, die nach Abschluss der Embryonalentwicklung im Organismus von Säugetieren vorkommen. Nach ihrem ontogenetischen Alter werden sie weiterhin in fötale, neonatale und adulte Stammzellen unterteilt. Durch einen noch nicht vollständig geklärten Mechanismus werden sie asymmetrisch geteilt, dabei entstehen eine identische Stammzelle und eine Progenitor-Tochterzelle. Die Progenitorzelle besitzt dabei bereits eine eingeschränkte Differenzierungspotenz. Man vermutet eine stufenweise Reduktion der Fähigkeiten bis zur terminalen Differenzierung, wobei unter Stresseinwirkung, wie Verletzung oder Zerstörung der Urzelle, eine Rückführung der Nachkommen in den Stammzellstatus möglich sein könnte.

Das Differenzierungspotenzial von postembryonalen Stammzellen ist auf die Ausreifung genetisch determinierter Gewebe beschränkt. Sie werden daher nicht als pluripotent, sondern nur noch als multipotent bezeichnet. Sie besitzen einige Eigenschaften embryonaler Zellen, nämlich die Fähigkeit zur Selbsterneuerung, Langlebigkeit, weisen ein hohes proliferatives Potenzial auf und sind in der Lage, sich in verschiedene Geweben umzuwandeln [8].

\section{Adulte Stammzellen}

$\nabla$

Aus adulten (somatischen) Stammzellen werden während der gesamten Lebensdauer des Organismus neue spezialisierte Zellen gebildet. Adulte Stammzellen, die in verschiedenen Organen zu finden sind, haben ein deutlich geringeres Selbsterneuerungsvermögen und ein eingeschränktes Differenzierungspotenzial in vitro im Vergleich zu embryonalen Stammzellen. So können adulte Stammzellen keine Keimblatt-überschreitende Differenzierung aufweisen. Adulte Stammzellen werden im Wesentlichen in einem Ruhezustand in mehreren Geweben bewahrt, sie können aber auf extrazelluläre Signale mit einer erneuten Stimulation der asymmetrischen Zellteilung reagieren. Innere und äußere Signale regulieren das Gleichgewicht der Selbsterneuerung und der Differenzierung adulter Stammzellen. Heute erfolgt die Gewinnung von adulten Stammzellen und von Progenitorzellen aus dem Knochenmark mittels Punktion des Beckenknochens. Die Gewinnung von Nabelschnurblut-Stammzellen nach der Abnabelung des Kindes wird von der Entnahme des restlichen, noch in Nabelschnur und Plazenta befindlichen Blutes begleitet. Seit über 40 Jahren werden die blutbildenden Stammzellen des Knochenmarks in der Behandlung von Leukämien und Lymphomen eingesetzt.

\section{Die Stammzellnische $\nabla$}

Adulte Stammzellen halten sich lebenslang in sogenannten „Nischen" auf [9]. Stammzellnischen werden aus Zellen zusammengesetzt, die den Stammzellen eine schützende Umgebung anbieten und sie von Signalen abtrennen, die sie herausfordern würden. Die Nische schützt daher auch vor übermäßiger Stammzel- 
Tab. 1 Epitheliale Stammzellen.

\begin{tabular}{|c|c|c|c|}
\hline Stammzellen & Herkunft & Differenzierung in & Markerexpression \\
\hline $\begin{array}{l}\text { Adulte epidermale Stammzellen } \\
\text { der interfollikulären Epidermis }\end{array}$ & $\begin{array}{l}\text { Maus, human } \\
\text { (Stratum basale) }\end{array}$ & $\begin{array}{l}\text { Epidermale Keratinozyten, } \\
\text { Sebozyten }\end{array}$ & $\begin{array}{l}\beta 1 \text {-Integrin(+), } \alpha 6 \text {-Integrin(+), Notch-signal- } \\
\text { ling-Ligand- } \delta 1(+), \text { CD200(+), C/EBP } \alpha / \beta\left(^{+}\right) \text {, } \\
\text { PPAR } \alpha(+), \operatorname{AP} 2 \alpha / \gamma(+) \text {, Melanom-assoziiertes } \\
\text { Chondroitinsulphatproteoglycan }(+) \text {, Lrig1(+), } \\
\text { CD71(-) }\end{array}$ \\
\hline $\begin{array}{l}\text { Epidermale Stammzellen } \\
\text { der Haarfollikel }\end{array}$ & $\begin{array}{l}\text { Maus, human } \\
\text { (Stratum basale) }\end{array}$ & $\begin{array}{l}\text { Follikuläre Keratinozyten, } \\
\text { intefollikuläre Keratinozyten }\end{array}$ & $\begin{array}{l}\text { Innenwurzelscheide: Notch-signalling-Ligand- } \\
\delta 1(+), \mathrm{BMP}(+), \mathrm{CDP}(+) \text {, GATA3(+); Haarschaft: } \\
\text { Wnt }(+), \text { Notch-signalling-Ligand- } \delta 1(+) \text {, Lef- } 1(+) \text {; } \\
\text { Matrix: Msx } 1 / 2(+) \text {, Ovo1(+), Foxn1(+), SHH(+) }\end{array}$ \\
\hline Stammzellen der Wulstregion & $\begin{array}{l}\text { Maus, human } \\
\text { (Wulstregion) }\end{array}$ & $\begin{array}{l}\text { Follikuläre Keratinozyten, } \\
\text { interfollikuläre Keratinozyten, } \\
\text { Sebozyten, Neuronen, } \\
\text { Schwann-Zellen }\end{array}$ & $\begin{array}{l}\text { CK15(+), CD200(+), } \beta 1 \text {-Integrin }(+), \text { WIF- } 1(+) \text {, } \\
\text { DKK-3(+), Dab-2(+), Srfp- } 1(+), \text { Lef- } 1(+), \beta-\text {-Cate- } \\
\text { nin }(+), \operatorname{TGF} \beta-2(+) \text {, Follistatin(+), DKK- } 1(-) \text {, } \\
\text { Tcf3(-) }\end{array}$ \\
\hline Talgdrüsenstammzellen & $\begin{array}{l}\text { Maus, human } \\
\text { (basale Talgdrüsenregion) }\end{array}$ & $\begin{array}{l}\text { Sebozyten, epidermale } \\
\text { Keratinozyten }\end{array}$ & $\begin{array}{l}\text { Blimp-1(+), c-Myc(+), Smad7(+), Smurf2(+), } \\
\text { IHH(+), PPAR } \gamma(+), \text { Wnt(-), Lef-1(-), } \beta \text {-Cate- } \\
\text { nin(-), Involucrin(-), Cornifin(-) }\end{array}$ \\
\hline
\end{tabular}

lenproduktion, die zu Tumoren führen könnte. Ein Dialog tritt zwischen Stamm- und Nischenzellen auf, um die lebenslangen Forderungen nach Zellregeneration zu erfüllen. Ein Gleichgewicht von Stammzellenruhe und Aktivität zu erhalten, ist das Kennzeichen einer funktionellen Nische.

\section{Reprogrammierung postembryonaler Stammzellen \\ $\nabla$}

Im Jahr 2007 ist es Yamanaka u. Mitarb. von der Universität Kyoto in Japan [10] und Thomson u. Mitarb. von der Universität von Wisconsin in Madison, USA [11], unabhängig von einander gelungen, menschliche Haut- und Bindegewebszellen umzuprogrammieren, d. h. Hautzellen bzw. andere Körperzellen erwachsener Menschen in induzierte pluripotente Stammzellen (iPS) umzuwandeln. Dabei sind vier zentrale, ruhende Entwicklungsgene in den Zellen aktiviert worden, sodass sie in eine Art embryonalen Zustand zurückversetzt wurden. Die Gruppe um Yamanaka verwendete für die Umprogrammierung von Hautzellen aus dem Gesicht einer 36-jährigen Frau die vier Gene, nämlich Oct3/4, Sox2, Klf4 und c-Myc, die auch bei Mäusezellen zum Erfolg geführt hatten [10]. Thomson und seine Kollegen nutzten ebenfalls zwei dieser Gene, Oct4, Sox2, ersetzten jedoch die anderen beiden durch zwei weitere Steuergene, nämlich Nanog und Lin28 [11]. Darüber hinaus wählten sie fötale Bindegewebszellen aus der Lunge und Zellen aus der Vorhaut eines neugeborenen Jungen für ihre Studie.

Mit beiden Methoden ließen sich die ursprünglich spezialisierten postembryonalen Zellen in einen sehr urtümlichen, undifferenzierten Zustand versetzen. So glichen nach der Behandlung unter anderem ihr Aussehen, ihre Oberflächenstruktur und bestimmte genetische Marker denen von embryonalen Stammzellen. Außerdem waren die Zellen in der Lage, sich in unterschiedliche Gewebetypen zu verwandeln [10,11].

Im Dezember 2007 berichteten Jänisch u. Mitarb. vom Whitehead Institute for Biomedical Research in Cambridge, Massachussets, USA [12], dass es ihnen gelungen ist, mit iPS-Zellen Mäuse zu heilen, die an Sichelzellenanämie gelitten hatten. Aus den aus dem Schwanz mittels Reprogrammierung gewonnenen iPS-Zellen entfernten sie das c-Myc-Gen, da sein Protein in Mäusen Tumoren verursachen kann, und im nächsten Schritt besei- tigten sie mittels homologer Rekombination das erkrankte Gen, das die Sichelzellenanämie auslöst, und ersetzten es durch die gesunde Erbanlage. Aus den so reparierten Stammzellen wurden blutbildende Vorläuferzellen gezüchtet, die sich zu verschiedenen Blut- und Immunzellen weiterentwickeln können. Die Vorläuferzellen wurden dann in die erkrankten Mäuse transplantiert, wo sie zu gesunden Blutzellen heranwuchsen. Die Symptome der Versuchstiere verschwanden durch die Behandlung nahezu vollständig.

\section{Epidermale Stammzellen \\ $\nabla$}

Die Epidermis ist ein sich ständig regenerierendes Epithel, welches sich in strikter Balance zwischen Proliferation und Differenzierung befindet. Diese lebenslang anhaltende Erneuerung beruht auf der Existenz von adulten epidermalen Stammzellen ( $\bullet$ Tab. 1). Aufgrund der unterschiedlichen Lokalisation entsprechender Stammzellklone unterscheidet man zwischen Stammzellen der interfollikulären Epidermis, der follikulären Epidermis und der Haarwulstregion.

Die interfollikuläre Epidermis stellt die erste Verteidigungslinie gegen Umweltnoxen dar und bildet deshalb eine wichtige Barriere des Körpers. Sie wird wiederholt im Laufe des Lebens erneuert. Das ständige Wachstum basaler Keratinozyten sichert die Homeostase der Haut. Sobald die Basalkeratinozyten die Basalzellschicht verlassen, um sich allmählich zur Hautoberfläche zu bewegen, schaltet der Zellzyklus ab und das Programm einer terminalen Differenzierung an. Nach der Aufnahme des Differenzierungsprogramms schreiten die Keratinozyten durch verschiedene Differenzierungstufen voran, um die drei charakteristischen Schichten der Epidermis zu bilden: das Stratum spinosum, das Stratum granulosum und letztlich das Stratum corneum. Im letzten Stadium verlieren die Keratinozyten allmählich ihre Kerne und wandeln sich in flache Korneozyten um. Die Korneozyten werden stetig von der Oberfläche abgestoßen.

Das Ersetzen terminal differenzierter Keratinozyten (Korneozyten) hängt von der Proliferation eines Teils der Basalkeratinozyten ab, die Eigenschaften von Stammzellen besitzen. Stammzellen der interfollikulären Epidermis befinden sich in der Basalschicht, wo sie an der darunter liegenden Basalmembran fixiert sind. Beim Modell, das am meisten akzeptiert ist, entstehen 
durch die Teilung einer solchen Stammzelle eine Tochterzelle, die postmitotische Zelle, und eine spezialisierte Stammzelle, die transient amplifizierende Zelle (TA-Zelle). Dabei ist die TA-Zelle direkter Nachkomme der epidermalen Stammzellen und besitzt ein hohes Proliferationspotenzial, das nach zwei bis fünf durchlaufenen Zellzyklen erschöpft wird. Die postmitotische Zelle steht wiederum kurz vor dem Eintritt in die suprabasalen Schichten und der damit verbundenen Enddifferenzierung [13]. Innerhalb der interfollikulären Epidermis existiert eine separate Stammzellpopulation. Markierungsstudien ergaben, dass, während multipotente Stammzellen der Wulstregion die Regeneration der Haarfollikel unterstützen, sie nicht dafür verantwortlich sind, die interfollikuläre Epidermis zu erneuern [14]. Darüber hinaus führt der Verlust der Zellen der Wulstregion in einem transgenen Mausmodell zu Verlust an Haarfollikelstrukturen, aber nicht zu Defekten der interfollikulären Epidermis [15].

Die Differenzierung epidermaler Stammzellen der Maus in Haarkeratinozyten und Sebozyten nach Stimulation mit entsprechenden mesenchymalen Signalen demonstriert, dass epidermale Stammzellen fähig sind, sich in Richtung verschiedener Zellabstammungen der Maushaut zu differenzieren [16]. Das große Potenzial der epidermalen Stammzellen als Reservoir für adulte Stammzellen und für therapeutische Anwendungen macht es erforderlich, diese innerhalb der Basalzellschicht zu identifizieren und zuverlässige Markermoleküle für ihre Isolierung nachzuweisen.

Forschung an der Maus- und menschlichen Epidermis hat gezeigt, dass die epidermalen TA-Zellen Zellklone bilden, die sich von der ursprünglichen Stammzelle bis zur Hornschicht der Haut ausdehnen. Diese Zellklone werden epidermale Proliferationseinheit (EPU) genannt. Das EPU-Modell impliziert, dass lediglich wenige TA-Zellen in der Basalmembran existieren, die von einem günstigen Mikromilieu umgeben sind, welches über alle erforderlichen Wege Signale für Stammzellaktivierung und -erneuerung liefert [17]. Das EPU-Modell wurde in letzter Zeit infrage gestellt, weil Zellabstammungsexperimente an Mäuseschwanzhaut gezeigt haben, dass eine spezialisierte Progenitorzellpopulation in der Lage ist, eine normale adulte Epidermis mit Ersatzzellen zu versorgen [18]. Es bleibt, eine mögliche Hierarchie von Progenitorzellpopulationen der menschlichen interfollikulären Epidermis nachzuweisen, nämlich ob ruhende primäre Stammzellen sowie spezialisierte und häufig aktivierte TA-Zellen existieren.

In-vivo-Ergebnisse von räumlichen Unterschieden bei der Expression von Stammzellenmarkermolekülen unterstützen das EPU-Modell. Zum Beispiel generieren menschliche Keratinozyten, die eine hohe Expression von $\beta 1$-Integrin aufweisen, große Kolonien von Keratinozyten in vitro (Kolonieformierungseffizienzverfahren), während solche Keratinozyten, die eine niedrige Expression von $\beta 1$-Integrin zeigen, kleine Zellklone bilden [19]. Weitere Merkmale epidermaler Stammzellen sind die hohe Expression von $\alpha 6$-Integrin, des notch-signalling-Liganden- $\delta 1$ und von CD200 sowie die niedrige Expression von CD71 [20-22]. Expression des Melanom-assoziierten Chondroitinsulphatproteoglycans und von Lrig1 wurden in ruhenden epidermalen Stammzellen nachgewiesen $[23,24]$.

\section{Stammzellen des Haarfollikels}

$\nabla$

\section{Follikulärer Zyklus}

Das Konzept des adulten Haarfollikels als Miniorgan, mit einem oberen, permanenten Teil und einem unteren, periodisch umgestaltenden Teil, den Anagenhaarbulbus, wird heute als Übersimplifizierung betrachtet [25]. Es gibt im Grunde genommen keinen Teil des Haarfollikels, der dem Umbauprozess während der zyklischen, prädeterminierten Organtransformation entkommt [26]. Die Regeneration des Anagenhaarfollikels ist das offensichtlichste von diesen periodischen Umbauereignissen. Solche Ereignisse erfordern die Existenz von vollständig funktionellen epithelialen Stammzellen. Einer Periode von apoptosegesteuerter epithelialer Zurückentwicklung (Katagenphase) und einer anschließenden Periode relativer Ruhe (Telogenphase) folgen die Entwicklung einer neuen Haarmatrix, einer Innen- und äuBeren Wurzelscheide und eines Haarschafts aus diesen epithelialen Stammzellen. Diese Ereignisse finden während jeder neuen Anagenphase unter der Steuerung eines induktiven, spezialisierten Mesenchyms statt [27].

\section{Epitheliale Stammzellen des Haarfollikels}

Epitheliale Stammzellen der interfollikulären Epidermis erneuern nicht die verlorenen Haarfollikel (z. B. bei vernarbenden Alopezien) [25]. Deshalb sind die epithelialen Stammzellen des Haarfollikels während der Haarfollikelentwicklung aber unter traumatischen und entzündlichen Stimuli darauf programmiert, sich ausschließlich in Haarfollikel zu differenzieren. Sie können aber reprogrammiert werden, alle Wege epithelialer Differenzierung zu realisieren [28]. Sie sind in der Lage, epidermale Defekte zu reepithelisieren, z. B. nach einer Hautverbrennung [29]. Auf diese Art haben epitheliale Stammzellen des Haarfollikels eine doppelte Funktion: Haarfollikelumbau im täglichen Leben und epidermale Regeneration, wenn die Hautintegrität schwer beschädigt wird. Die Produktion des Haarschafts und die zyklische Entwicklung des Follikels setzen eine enge Interaktion mit dem nahe liegenden, spezialisierten Mesenchym voraus, wobei das Mesenchym auch wesentliche zyklische Umbauvorgänge durchläuft.

\section{Die Wulstregion}

Bei Mensch und Tier findet man im Bereich zwischen den zyklisch erneuernden und ruhenden Teilen der äußeren Wurzelscheide eine Zellansammlung, die Wulstregion, welche langsam zyklisch wächst. Sie befindet sich im Haar-Isthmus, welcher den Abschnitt des Haarfollikels zwischen Einmündung des Ausführungsgangs der Talgdrüse (Ductus seboglandularis) von oben und der Ansatzstelle des M. arector pili von unten darstellt. Cytokeratin-15 und CD200 sind Marker zur Identifizierung der Zellen der Wulstregion $[22,30]$.

Die Zellen der Wulstregion waren die ersten adulten Stammzellen, die identifiziert wurden [31]. Sie sind in der Lage, Haarfollikel, interfollikuläre Epidermis und Talgdrüsen zu generieren $[32,33]$. Außerdem sind epitheliale Stammzellen der Wulstregion des murinen Haarfollikels in der Lage, auch nicht-epitheliale Zellen wie Neurone oder Schwann-Zellen zu generieren [34], ein Potenzial, das auf abstammungsunabhängige pluripotente Eigenschaften hinweist. Im Vergeich zu Zellen aus anderen Regionen des Haarfollikels und der Epidermis besitzen sie die größte Wachstums- und klonogene Kapazität in vitro. Sie produzieren den unteren Teil des Haarfollikels, einschließlich der äuBeren Wurzelscheide, der Matrix und der Medulla [15]. 
Tab. 2 Dermale Stammzellen.

\begin{tabular}{|c|c|c|c|}
\hline Stammzellen & Herkunft & Differenzierung in & Markerexpression \\
\hline Multipotente Dermalzellen & $\begin{array}{l}\text { Maus, human } \\
\text { (Dermis) }\end{array}$ & $\begin{array}{l}\text { Chondrozyten, Osteoblasten, } \\
\text { Adipozyten, Muskelzellen, Endothel- } \\
\text { zellen, Mastzellen, Vorstufen von } \\
\text { hämatopoetischen Zellen, } \\
\text { Hepatozyten, Nervenzellen }\end{array}$ & $\begin{array}{l}\text { CD13(+), CD29(+), CD49(+), CD105(+), } \\
\text { CD34(+), Nestin(-), Vimentin(+), Stro-1(+), } \\
\text { CD45(-), CD106(-), CD133(-) }\end{array}$ \\
\hline $\begin{array}{l}\text { Dermis-abstammende } \\
\text { multipotente Stammzellen }\end{array}$ & $\begin{array}{l}\text { Ratte } \\
\text { (Dermis) }\end{array}$ & $\begin{array}{l}\text { Chondrozyten, Osteoblasten, } \\
\text { Adipozyten, Pankreaszellen, } \\
\text { Hepatozyten, Nervenzellen }\end{array}$ & $\begin{array}{l}\text { CD59(+), CD90(+), CD44(+), VCAM-I(+), } \\
\text { ICAM-I(+), CK-19(-), CD31(-), CD45(-), } \\
\text { CD34(-), } \alpha-S M A(-) \text {, Desmin(-), Kollagen- } \\
\text { Typ-II(-) }\end{array}$ \\
\hline $\begin{array}{l}\text { Hautabstammende Progenitorzellen } \\
\text { (Stammzellen der dermalen Papilla) }\end{array}$ & $\begin{array}{l}\text { Maus, human } \\
\text { (Dermis) }\end{array}$ & $\begin{array}{l}\text { Adipozyten, Muskelzellen, } \\
\text { Nervenzellen (Gliazellen, } \\
\text { Schwann-Zellen) }\end{array}$ & $\begin{array}{l}\text { Nestin(+), Fibronectin(+), Vimentin(+), } \\
\text { Slug(+), Snail(+), Twist(+), Pax3(+), Sox } 9(+)\end{array}$ \\
\hline Fibrozyten & Human (Blut) & Fibroblasten & $\begin{array}{l}\text { CD34(+), CD11b }(+), \text { CD45(+), HLA-DR(+), } \\
\text { CD71(+), CD80(+), CD86(+), Kollagen- } \\
\text { Typ-I, III(+), Vimentin(+) }\end{array}$ \\
\hline
\end{tabular}

Während die Wulstregion Stammzellen enthält, repräsentiert die Haarmatrix ein proliferierendes und differenziendes TA-Zellkompartiment [35]. Humane telogene und anagene Haarfollikel exprimieren Cytokeratin-15 und weisen eine starke Expression von $\beta 1$-Integrin in der Basalschicht der Zellen auf, die um das Telogenhaar und die anagene Wulstregion lokalisiert ist [36]. In der Katagenphase des Haarzyklus verschwindet der untere Teil des follikulären Epithels, während der Restfollikel reich an Stammzellen ist. Die epidermalen Stammzellen, die an der Basis des Anagenhaarbulbus versammelt sind, stellen schnell proliferierende TA-Zellen dar, die sich in Richtung aller Epithelschichten des Follikels differenzieren.

\section{Molekulare Steuerungen der epidermalen Stammzellen des Haarfollikels}

Der Haarfollikel verliert nie seine regenerative Kapazität, es sei denn, dass die Stammzellen zerstört werden. Dies impliziert, dass die epidermalen Stammzellen des Haarfollikels in ihrem undifferenzierten Zustand - kontrolliert durch entsprechende Signale - für die Gesamtdauer des Lebens verbleiben. Andererseits kann eine Überaktivierung dieser Zellen zu überaktiven Progenitorzellen und damit zu einer Tumorentwicklung führen. In der Haarfollikelwulstregion werden Wnt-Inhibitoren exprimiert; eine hohe Expression von Wnt-Inhibitory-Factor-1 (WIF-1) und Dickkopf-3 (DKK-3) wurden nachgewiesen. Bei der Maus werden Transkripte, die die Wnt-Inhibitoren hoch exprimieren, z.B. DKK-3, Disabled-2 (Dab-2) und secreted-frizzledrelated-protein-1 (Sfrp-1), nachgewiesen [25]. Überexpression von Lymphocyte-enhancer-factor-1 (Lef-1) oder $\beta$-Catenin in transgenen Mäusen führt zu ektopischer Bildung abnormaler Haarfollikel im interfollikulären und oralen Epithelium, während genetisch defektes Lef-1 zum Stoppen der follikulären Entwicklung und Haarlosigkeit führt [37,38]. Ebenso, wenn das $\beta$-Catenin defekt ist oder wenn der Wnt-Signalweg durch ektopische Expression von DKK1 gehemmt wird, bilden sich keine Vorstufen reifer Haare während der Embryogenese. Es liegt nahe, dass der Wnt-Signalweg eine große Rolle in der follikulären Morphogenese und zyklischen Entwicklung spielt [39]. In der Abwesenheit von Wnt-Signalen übernimmt der Transkriptionsfaktor-3 (Tcf3) die Erhaltung des undifferenzierten Status der epidermalen Stammzellen, während die Einschaltung von WntSignalen diese Zellen in die Richtung der follikulären Keratinozyten differenzieren lässt [40].
Die Tatsache, dass humane Zellen der Wulstregion Tumorwuchsfaktor- $\beta-2$ (TGF $\beta-2$ ) exprimieren, unterstützt das Bestehen eines ruhenden Stammzellphänotyps [22,25]. Allerdings ist TGF $\beta$ ein pleiotropisches Protein, das die Proliferation epithelialer Zellen stimuliert. Die Produktion des Haarschaftes in der Anagenphase und der Beginn eines neuen Haarzyklus in der Telogenphase sind Ergebnisse einer doppelten Interaktion zwischen den dermalen Papillenzellen und den überlagernden epithelialen Zellen. Lösliche Faktoren, wie diese der morphogenen Proteine des Knochens (BMP), spielen eine wichtige Rolle in der Regulation dieser Interaktion. BMP und Aktivine sind Mitglieder der TGF $\beta$-Familie. Der Antagonist des Aktivin-BMP-Signalweges Follistatin ist in der Wulstregion überexprimiert. Die Blockade des Aktivin-BMP-Signalweges durch Follistatin könnte die ruhenden Stammzellen fördern.

\section{Dermale Stammzellen}

Die Fibroblasten sind zusammen mit den Chondrozyten und Osteoblasten Zellen mesodermaler Herkunft. Fibroblasten sind die Hauptstrukturzellen der Dermis. Sie produzieren Glykosaminoglykane, Elastin, Fibronektin, Laminin und das wichtigste dermale Strukturprotein, das Kollagen ( Tab. 2). Weiterhin produzieren Fibroblasten verschiedene lösliche Faktoren, die in der Haut aktiv sind, wie Prostaglandine, Leukotriene und Zytokine $[41,42]$. Weitere Zellen wie Keratinozyten und Mastzellen kooperieren mit den Fibroblasten, um die Hauthomeostase zu bewahren $[41,43]$.

Obwohl Fibroblasten eine wichtige Rolle für die dermale Homeostase spielen, fehlen wichtige Informationen über ihre Funktionen. Meistens fehlt die Information über die Art, mit der Fibroblasten die regenerative Fähigkeit der Haut kontrollieren. Aktuelle Arbeiten haben das Vorhandensein von undifferenzierten Zellen (Stammzellen) in allen dermalen Geweben gezeigt, die signifikant beim Erhalt der Homeostase und der Regeneration der verletzten Haut wirken. Eine klonale Analyse durch Chen u. Mitarb. [44] hat gezeigt, dass 6,4\% der dermalen Klone, die aus einer einzigen Zelle stammen, tripotent sind und dass dermale Stammzellen ca. 0,3\% der humanen dermalen Fibroblasten der Vorhaut ausmachen. Mithilfe des Insulin-ähnlichen Wuchsfaktors (IGF), des Fibroblastenwuchsfactors- $\beta$-2 (FGF $\beta-2$ ) und FGF $\beta-27$ haben Toma u. Mitarb. [45] und Biernaskie et al. 
[46] erfolgreich multipotente Zellen (Progenitorzellen) aus humaner Dermis kultiviert. Solche undifferenzierte dermale Zellen werden Fibrozyten genannt und sind Progenitorzellen der Fibroblasten. Sie emigrieren aus dem Knochenmark oder dem peripheren Blut in den Ort der Hautverletzung, infiltrieren die Dermis und beteiligen sich an der Wundheilung [47,48]. Die Beziehung zwischen Fibrozyten und Stammzellen der Dermis ist allerdings wenig bekannt. Dermale Stammzellen sind fähig, Nestin, Fibronektin und Vimentin wie auch andere Markerproteine zu produzieren, und sind in der Lage, sich in Adipozyten, Osteoblasten, Muskelzellen, Leberzellen und Nervenzellen zu differenzieren [44-49]. Obwohl dermale Zellen mesodermaler Herkunft sind, differenzieren dermale Stammzellen in den endodermalen Leberzellen und den ektodermalen Nervenzellen, ein Beweis für die Fähigkeit dermaler Stammzellen als multipotente Zellen über ihre Abstammungslinie zu differenzieren.

\section{Stammzellen der dermalen Papilla}

Die zyklische Regeneration des Haarfollikels ist von einer exakten Interaktion eines spezialisierten Mesenchyms mit dem epithelialen Anteil des Haarfollikels abhängig. Der mesenchymale Anteil ist auch einer zyklischen Regeneration unterworfen. Die Zellproliferation und Apoptose der mensenchymalen follikulären Zellen, d.h. der Bindegewebsscheide und der dermalen Papilla, sind viel weniger intensiv und finden in engen Zeitfenstern zwischen den Ruhephasen statt [26].

Während der Anagenphase regenerieren die Bindegewebsscheide und die dermale Papilla und darüber hinaus expandieren sie [50]. Die Bindegewebsscheide dient als Quelle für die Bildung von Granulationsgewebe unter Beteiligung von Fibroblasten, Endothelzellen, Mastzellen und Makrophagen [51]. Die Anagenphase ist mit einer signifikanten Angiogenese assoziiert. Die neuen Gefäße entstehen aus dermalen Stammzellen der Bindegewebsscheide [52]. Die Bildung von reifen Mastzellen, Adipozyten oder Chondrozyten wie auch von Vorstufen von hämatopoetischen und neuronalen Zellen - neben der Bildung von Fibroblasten - beweisen die Pluripotenz dieser mesenchymalen Stammzellen [52,53]. Die molekulare Analyse der Expressionsmarker dieser Zellen zeigte eine stetige Expression von Lef-1, ein Protein des Wnt/ $\beta$-Catenin-Signalweges [54]. Sie konnten sich auf Laminin unter Präsenz von FGF $\beta$-2 in neuralen Zellen differenzieren [55]. Fernandes u. Mitarb. [56] haben eine dermale Zellpopulation nachgewiesen, die sowohl eine neuronale als auch eine mesodermale Differenzierung vollziehen konnte. Diese sogenannten hautabstammenden Progenitorzellen wurden in der dermalen Papilla lokalisiert und exprimieren Proteine wie Versican und Nexin [55].

\section{Talgdrüsenstammzellen}

$\nabla$

\section{Talgdrüsenentwicklung und Zelldifferenzierung}

Die Entwicklung der Talgdrüsen ist eng mit der Differenzierung der anderen zwei epithelialen Abstammungslinien, Haarfollikeln und Epidermis, verwandt [57]. Zwischen der 10. und 12. Woche des fötalen Lebens wird ein Stratum intermedium erkennbar. Während dieser Zeit wird die Entwicklung einer Haaranlage prominent. In den folgenden Wochen wächst die Haaranlage Richtung Dermis und ein Ansatz einer Talgdrüse wird ersichtlich. Von der 13. bis 15. Woche entwickelt sich die Talgdrüse aus der Haaranlage. Die Zellen der Talgdrüsenanlage sind mit denen der Basalschicht der Epidermis und des follikulären Kanals identisch.

\section{Existenz einer Talgdrüsenstammzelllinie}

Die stetige Differenzierung der Talgdrüsenzellen setzt eine Zellquelle mit Stammzelleigenschaften voraus. Aktuelle Daten über das Kompartiment der epidermalen Stammzellen weisen auf das Vorhandensein einer speziellen Population von Talgdrüsenstammzellen hin $[28,58]$. Von allen epithelialen Stammzellpopulationen ist diese der Talgdrüse am wenigsten charakterisiert. Es gibt gute Beweise für eine Kommunikation der Talgdrüsenzellen mit denen des Haarfollikels. Unter Normalbedingungen und als Reaktion auf Hautverletzungen oder entzündliche Stimuli übernehmen Stammzellen die separate Produktion differenzierter epithelialer Zellen $[15,59,60]$. Im Fall, dass eines der beiden Organe untergeht, übernimmt die andere Zellpopulation den Wiederaufbau [61]. Allerdings haben die Stammzellen der Wulstregion die Kapazität, sich in Talgdrüsenzellen zu differenzieren und eine Talgdrüse entstehen zu lassen.

In der Talgdrüse existiert eine unipotente Stammzellpopulation, sowohl bei den Säugetieren als auch beim Menschen. Eine Sammlung langsam wachsender Zellen an der Basis der Talgdrüse der Maus, die das transkriptionelle Rezeptor B-Lymphozyteninduzierte Reifungsprotein-1 (Blimp-1) exprimieren, werden als die Progenitorzellen der Talgdrüse betrachtet [62,63]. Da keine Konversation zwischen Blimp-1 und c-Myc stattfindet, müssen andere Faktoren das c-Myc-Protein in den Talgdrüsenzellen regulieren [60].

\section{Talgdrüsenstammzellen weisen Eigenschaften} multipotenter epidermaler Stammzellen auf

Nach Injektion von immortalisierten humanen SZ95-Talgdrüsenzellen in die Haut der nackten Maus konnten Kolonien menschlicher Talgdrüsenzellen entstehen, umgeben von menschlichen Zellen, die Involucrin und Cornifin exprimierten [60]. Die letzten sind Differenzierungsmarker der interfollikulären Epidermis und der Innenwurzelscheide des Haarfollikels. Befunde über die Entwicklung von Talgdrüsenzellansammlungen in der interfollikulären Epidermis der Maus durch die Aktivierung von c-Myc und solche über die Umwandlung von Talgdrüsenzellen in Keratinozyten der interfolikulären Epidermis durch die Aktivierung des Hedgehog-Signalweges unterstützen die Existenz multipotenter Talgdrüsen-Progenitorzellen $[62,64]$.

\section{Wege der Talgdrüsenzelldifferenzierung}

In transgenen Mausmodellen übt die gleichzeitige Aktivierung von c-Myc und $\beta$-Catenin entgegengesetzte Effekte auf die sebozytäre Differenzierung aus. c-Myc blockiert die ektope Bildung von Haarfollikeln und $\beta$-Catenin reduziert die Talgdrüsenzelldifferenzierung [60]. Die Aktivierung von c-Myc fördert die Differenzierung in Richtung der interfollikulären Epidermis und der Talgdrüse und führt zur Entwicklung von differenzierten Talgdrüsenzellen innerhalb der interfollikulären Epidermis $[29,59]$. Die entgegengesetzten Wirkungen von c-Myc und $\beta-\mathrm{Ca}-$ tenin bei der Talgdrüsenzelldifferenzierung waren aus der bisherigen Literatur nicht zu erwarten, weil c-Myc als $\beta$-CateninZielgen im Darmepithelium betrachtet wurde.

Aktuelle Untersuchungen haben gezeigt, dass die Hemmung des Wnt-Signalweges die Talgdrüsendifferenzierung fördert. Eine dominante negative Lef-1-Mutation hemmt die follikuläre Differenzierung und stimuliert den Aufbau von Talgdrüsen und der interfollikulären Epidermis [59]. Außerdem führen dominante negative Mutationen zur Talgdrüsentumorigenese bei Mensch und Maus [65]. Die negative Rolle des Wnt-Signalweges hängt 
mit einer Expression von $\beta$-Catenin zusammen: Die Expression von NLef-1 führt zur Abnahme der $\beta$-Catenin-Expression und zur Überexpression von Smad7, welches für den Abbau von $\beta$-Catenin durch einen neuartigen Mechanismus verantwortlich ist. Es handelt sich um die Vermittlung der Wirkung durch das Smad-spezifische E3-Ubiquitin-Proteinligase-2 (Smurf2), das auch eine Talgdrüsenhyperplasie induziert [66]. Der Wnt-Signalweg ist auch mit dem Hedgehog-Signalweg verbunden. Eine Überexpression von NLef-1 führt zur Überexpression des IndianHedgehog (IHH) in SZ95-Sebozyten [59]. Die zeitliche Korrelation und die Balance zwischen Hedgehog- und Wnt-Signalwegen sind für die normale Talgdrüsenzelldifferenzierung entscheidend. Der Hedgehog-Signalweg ist an der Talgdrüsenzellproliferation auch beteiligt. Die Expression eines mutierten Smoothen-Rezeptors, welcher den Hedgehog-Signalweg stetig stimuliert, führt zur ektopen Talgdrüsendifferenzierung [64]. Im Gegensatz dazu könnte die Hemmung des Hedgehog-Signalweges durch Überexpression eines dominanten negativen $\mathrm{Mu}-$ tanten von Gli-2, eines transkriptionalen Hedgehog-Effektors, die Talgdrüsenzellentwicklung hemmen.

\section{Klinische Bedeutung der Stammzellen der Haut $\nabla$}

Die Selbsterneuerung und multipotente Differenzierung der Hautstammzellen, sowohl fötaler als auch adulter Herkunft, hebt diese Zellen zu einem sehr attraktiven Instrument der Alterungsforschung in der regenerativen Medizin, der Gewebeersatzforschung, der Gentherapie und der Therapie mit autologen adulten Stammzellen auf. Andererseits wird die Identifizierung multipotenter Stammzellen der Haut die dermatologische Forschung revolutionieren und neue Wege für individuelle Medikamententestungen und Überprüfung der kutanen Pharmakogenomik öffnen.

Zellmodelle, wie das der immortalisierten humanen SZ95Talgdrüsenzelllinie, die in der Lage sind, sowohl in Sebozyten als auch in follikuläre Keratinozyten zu differenzieren, bieten ein erstes Instrument für die Erforschung der epidermalen Abstammungsselektion und ihrer Rolle beim Alterungsprozess an. Damit wird die Stammzellforschung der Haut das allgemeine Interesse in der Dermatologie fördern, Wissenschaftler aus der Basisforschung und klinischen Medizin für sich gewinnen und die Grenzen der traditionellen dermatologischen Forschung und Pharmakologie überschreiten.

\section{Danksagung \\ $\nabla$}

Diese Arbeit wurde anlässlich des 10-jährigen Jubiläums und zur Anerkennung der Förderung der dermatologischen Forschung durch die Berliner Stiftung für Dermatologie verfasst.

\section{Abstract}

\section{Epidermal Stem Cells and their Importance in Dermatology}

Skin integrity is maintained by epidermal stem cells, which selfrenew and generate daughter cells that undergo terminal differentiation. Existence of several distinct skin stem cell populations has been reported. Genetic labelling studies detected multipotent stem cells of the hair follicle, which support regeneration of hair follicles but is not responsible for maintaining interfollicular epidermis. The latter exhibits a distinct stem cell population. However, whenever skin integrity is severely compromised, e.g. after burns, hair follicle stem cells remodel epidermal regeneration. On the other hand, bulge cells, the first adult stem cells of the skin to have been identified, are capable of forming hair follicles, interfollicular epidermis and sebaceous glands. In addition - at least in mouse hair follicles - they can also give rise to non-epithelial cells, indicating a lineage-independent pluripotent character. Multipotent cells (skin-derived precursor cells) are present in human dermis. Dermal stem cells represent $0.3 \%$ among human dermal foreskin fibroblasts. A resident pool of progenitor cells exists within the sebaceous glands, which is able to differentiate into both sebocytes and interfollicular epidermis. The self-renewal and multi-lineage differentiation of skin stem cells make these cells attractive for regenerative medicine, tissue repair, gene therapy and cell-based therapy with autologous adult stem cells.

\section{Literatur}

1 Hübner K, Fuhrmann G, Christenson LK, Kehler J, Reinbold R, De La Fuente R, Wood J, Strauss JF 3rd, Boiani M, Schöler HR. Derivation of oocytes from mouse embryonic stem cells. Science 2003; 300: 1251-1256

2 Thomson JA, Itskovitz-Eldor J, Shapiro SS, Waknitz MA, Swiergiel JJ, Marshall VS, Jones JM. Embryonic stem cell lines derived from human blastocysts. Science 1998; 282: 1145 - 1147

3 Adjaye J, Huntriss J, Herwig R, BenKahla A, Brink TC, Wierling C, Hultschig C, Groth D, Yaspo ML, Picton HM, Gosden RG, Lehrach H. Primary differentiation in the human blastocyst: comparative molecular portraits of inner cell mass and trophectoderm cells. Stem Cells 2005; 23: $1514-1525$

4 Martin GR. Isolation of a pluripotent cell line from early mouse embryos cultured in medium conditioned by teratocarcinoma stem cells. Proc Natl Acad Sci USA 1981; 78: 7634-7638

5 Smith AG, Heath JK, Donaldson DD, Wong GG, Moreau J, Stahl M, Rogers $D$. Inhibition of pluripotential embryonic stem cell differentiation by purified polypeptides. Nature 1988; 336: 688-690

6 Schnieke AE, Kind AJ, Ritchie WA, Mycock K, Scott AR, Ritchie M, Wilmut I, Colman A, Campbell KH. Human factor IX transgenic sheep produced by transfer of nuclei from transfected fetal fibroblasts. Science 1997; 278: $2130-2133$

7 Mitalipov SM, Zhou Q Byrne JA, Ji WZ, Norgren RB, Wolf DP. Reprogramming following somatic cell nuclear transfer in primates is dependent upon nuclear remodeling. Hum Reprod 2007; 22: 2232 - 2242

8 Sharpless NE, DePinho RA. How stem cells age and why this makes us grow old. Nat Rev Mol Cell Biol 2007; 8: $703-713$

9 Moore KA, Lemischka IR. Stem cells and their niches. Science 2006; 311: $1880-1885$

10 Takahashi K, Tanabe K, Ohnuki M, Narita M, Ichisaka T, Tomoda K, Yamanaka $S$. Induction of pluripotent stem cells from adult human fibroblasts by defined factors. Cell 2007; 131: $861-872$

11 Yu J, Vodyanik MA, Smuga-Otto K, Antosiewicz-Bourget J, Frane JL, Tian S, Nie J, Jonsdottir GA, Ruotti V, Stewart R, Slukvin II, Thomson JA. Induced pluripotent stem cell lines derived from human somatic cells. Science 2007; 318: 1917-1920

12 Hanna J, Wernig M, Markoulaki S, Sun CW, Meissner A, Cassady JP, Beard C, Brambrink T, Wu LC, Townes TM, Jaenisch R. Treatment of sickle 
cell anemia mouse model with iPS cells generated from autologous skin. Science 2007; 318: 1920-1923

13 Fuchs E. Skin stem cells: rising to the surface. J Cell Biol 2008; 180: $273-284$

14 Levy V, Lindon C, Zheng Y, Harfe BD, Morgan BA. Epidermal stem cells arise from the hair follicle after wounding. Dev Cell 2007; 9: 855 -861

15 Ito $M$, Kizawa K, Hamada $K$, Cotsarelis G. Hair follicle stem cells in the lower bulge form the secondary germ, a biochemically distinct but functionally equivalent progenitor cell population, at the termination of catagen. Differentiation 2004; 72: $548-557$

16 Niemann C, Watt FM. Designer skin: lineage commitment in postnatal skin. Trends Cell Biol 2002; 12: 185 - 192

17 Potten CS. The epidermal proliferative unit: the possible role of the central basal cell. Cell Tissue Kinet 1974; 7: 77-88

18 Clayton E, Doupe DP, Klein AM, Winton DJ, Simons BD, Jones PH. A single type of progenitor cell maintains normal epidermis. Nature 2007; 446: $185-189$

19 Jones PH, Watt FM. Separation of human epidermal stem cells from transit amplifying cells on the basis of differences in integrin function and expression. Cell 1993; 73: $713-724$

20 Li A, Simmons PJ, Kaur P. Identification and isolation of candidate human keratinocyte stem cells based on cell surface phenotype. Proc Natl Acad Sci USA 1998; 95: 3902 - 3907

21 Lowell S, Jones P, LeRoux I, Dunne J, Watt FM. Stimulation of human epidermal differentiation by delta-notch signalling at the boundaries of stem-cell clusters. Curr Biol 2000; 10: $491-500$

22 Ohyama M, Terunuma A, Tock CL, Radonovich MF, Pise-Masison CA, Hopping SB, Brady JN, Udey MC, Vogel JC. Characterization and isolation of stem cell-enriched human hair follicle bulge cells. J Clin Invest 2006; 116: 249-260

23 Legg J, Lensen UB, Broad S, Leigh I, Watt FM. Role of melanoma chondroitin sulphate proteoglycan in patterning stem cells in human interfollicular epidermis. Development 2003; 130: 6049-6063

24 Jensen KB, Watt FM. Single-cell expression profiling of human epidermal stem and transit-amplifying cells: Lrig1 is a regulator of stem cell quiescence. Proc Natl Acad Sci USA 2006; 103: 11958 - 11963

25 Tiede S, Kloepper JE, Bodo E, Tiwari S, Kruse C, Paus R. Hair follicle stem cells: Walking the maze. Eur J Cell Biol 2007; 86: 355 - 376

26 Paus $R$, Foitzik K. In search of the "hair cycle clock": a guided tour. Differentiation 2004; 72: 489-511

27 Cotsarelis G, Sun TT, Lavker RM. Label-retaining cells reside in the bulge area of pilosebaceous unit: implications for follicular stem cells, hair cycle, and skin carcinogenesis. Cell 1990; 61: 1329-1337

28 Fuchs E, Horsley V. More than one way to skin... Genes \& Devel 2008; 22: $976-985$

29 Ito M, Liu Y, Yang Z, Nguyen J, Liang F, Morris RJ, Cotsarelis G. Stem cells of the hair follicle contribute to wound repair but not to homeostasis of the epidermis. Nat Med 2005; 11: $1351-1354$

30 Lyle S, Christofidou-Solomidou M, Liu Y, Elder DE, Albelda S, Cotsarelis G. Human hair follicle bulge cells are biochemically distinct and possess an epithelial stem cell phenotype. J Invest Dermatol Symp Proc 1999; 4: $296-301$

31 Cotsarelis G. Epithelial stem cells: a folliculocentric view. J Invest Dermatol 2006; 126: 459-468

32 Oshima H, Rochat A, Kedzia C, Kobayashi K, Barrandon Y. Morphogenesis and renewal of hair follicles from adult multipotent stem cells. Cell 2001; 104: 233-245

33 Liu Y, Lyle S, Yang Z, Cotsarelis G. Keratin 15 promoter targets putative epithelial stem cells in the hair follicle bulge. J Invest Dermatol 2003; 121: $963-968$

34 Hoffman RM. The pluripotency of hair follicle stem cells. Cell Cycle 2006; 5: $232-233$

35 Roh C, Tao Q Photopoulos C, Lyle S. In vitro differences between keratinocyte stem cells and transitamplifying cells of the human hair follicle. J Invest Dermatol 2005; 125: 1099-1105

36 Lyle S, Christofidou-Solomidou M, Liu Y, Elder DE, Albelda S, Cotsarelis G. The C8/144B monoclonal antibody recognizes cytokeratin 15 and defines the location of human hair follicle stem cells. J Cell Sci 1998; 111: $3179-3188$

37 vanGenderen C, Okamura RM, Farinas I, Quo RG, Parslow TG, Bruhn L, Grosschedl $R$. Development of several organs that require inductive epithelial-mesenchymal interactions is impaired in LEF-1-deficient mice. Genes Dev 1994; 8: 2691 - 2703
38 Gat U, DasGupta R, Degenstein L, Fuchs E. De novo hair follicle morphogenesis and hair tumors in mice expressing a truncated beta-catenin in skin. Cell 1998; 95: 605-614

39 O'Shaughnessy RF, Yeo W, Gautier J, Jahoda CAB, Christiano AM. The WNT signalling modulator, wise, is expressed in an interaction-dependent manner during hair-follicle cycling. J Invest Dermatol 2004; 123: $613-621$

40 Nguyen H, Rendl M, Fuchs E. Tcf3 governs stem cell features and represses cell fate determination in skin. Cell 2006; 127: 171 - 183

41 Artuc M, Steckelings UM, Henz BM. Mast cell-fibroblast interactions: human mast cells as source and inducers of fibroblast and epithelial growth factors. J Invest Dermatol 2002; 118: 391 - 395

42 Werner S, Krieg T, Smola H. Keratinocyte-fibroblast interactions in wound healing. J Invest Dermatol 2007; 127: 998-1008

43 Stark HJ, Willhauck MJ, Mirancea N, Boehnke K, Nord I, Breitkreutz D, Pavesio A, Boukamp P, Fusenig NE. Authentic fibroblast matrix in dermal equivalents normalises epidermal histogenesis and dermoepidermal junction in organotypic co-culture. Eur J Cell Biol 2004; 83: 631 645

44 Chen FG, Zhang WJ, Bi D, Liu W, Wei X, Chen FF, Zhu L, Cui L, Cao Y. Clonal analysis of nestin(-) vimentin(+) multipotent fibroblasts isolated from human dermis. J Cell Sci 2007; 120: 2875 - 2883

45 Toma JG, Akhavan M, Fernandes KJ, Barnabé-Heider F, Sadikot A, Kaplan $D R$, Miller FD. Isolation of multipotent adult stem cells from the dermis of mammalian skin. Nat Cell Biol 2001; 3: 778-784

46 Biernaskie JA, McKenzie IA, Toma JG, Miller FD. Isolation of skin-derived precursors (SKPs) and differentiation and enrichment of their Schwann cell progeny. Nat Protoc 2006; 1: $2803-2812$

47 Bucala R, Spiegel LA, Chesney J, Hogan M, Cerami A. Circulating fibrocytes define a new leukocyte subpopulation that mediates tissue repair. Mol Med 1994; 1: $71-81$

48 Quan TE, Cowper S, Wu SP, Bockenstedt LK, Bucala R. Circulating fibrocytes: collagen-secreting cells of the peripheral blood. Int J Biochem Cell Biol 2004; 36: 598-606

49 Shi CM, Cheng TM. Differentiation of dermis-derived multipotent cells into insulin-producing pancreatic cells in vitro. World J Gastroenterol 2004; 10: $2550-2552$

50 Tobin DJ, Gunin A, Magerl M, Paus R. Plasticity and cytokinetic dynamics of the hair follicle mesenchyme during the hair growth cycle: implications for growth control and hair follicle transformations. J Invest Dermatol Symp Proc 2003; 8: 80-86

51 Jahoda CAB, Reynolds AJ. Hair follicle dermal sheath cells: unsung participants in wound healing. Lancet 2001; 358: $1445-1448$

52 Jahoda CAB, Whitehouse CJ, Reynolds AJ, Hole N. Hair follicle dermal cells differentiate into adipogenic and osteogenic lineages. Exp Dermatol 2003; 12: 849-859

53 Kumamoto T, Shalhevet D, Matsue H, Mummert ME, Ward BR, Jester JV, Takashima A. Hair follicles serve as local reservoirs of skin mast cell precursors. Blood 2003; 102: 1654-1660

54 DasGupta R, Fuchs E. Multiple roles for activated LEF/TCF transcription complexes during hair follicle development and differentiation. Development 1999; 126: $4557-4568$

55 Richardson GD, Arnott EC, Whitehouse CJ, Lawrence CM, Reynolds AJ, Hole N, Jahoda CAB. Plasticity of rodent and human hair follicle dermal cells: implications for cell therapy and tissue engineering. J Invest Dermatol Symp Proc 2005; 10: 180- 183

56 Fernandes KJ, McKenzie IA, Mill P, Smith KM, Akhavan M, Barnabe-Heider F, Biernaskie J, Junek A, Kobayashi NR, Toma JG, Kaplan DR, Labosky $P A$, Rafuse V, Hui CC, Miller FD. A dermal niche for multipotent adult skin-derived precursor cells. Nat Cell Biol 2004; 6: 1082 - 1093

57 Zouboulis CC. Acne and sebaceous gland function. Clin Dermatol 2004; 22: 360 - 366

58 Watt FM, Lo Celso C, Silva-Vargas V. Epidermal stem cells: an update. Curr. Opin. Genetics Develop 2006; 16: 518 - 524

59 Niemann C, Unden AB, Lyle S, Zouboulis CC, Toftgård R, Watt FM. Indian hedgehog and beta-catenin signaling: Role in the sebaceous lineage of normal and neoplastic mammalian epidermis. Proc Natl Acad Sci USA 2003; 100 (suppl 1): $11873-11880$

60 Lo Celso C, Berta MA, Braun KM, Frye M, Lyle S, Zouboulis CC, Watt FM. Characterisation of bipotential epidermal progenitors derived from human sebaceous gland: contrasting roles of c-Myc and beta-catenin. Stem Cells 2008; 26: 1241 - 1252

61 Selleri S, Seltmann H, Gariboldi S, Shirai YF, Balsari A, Zouboulis CC, Rumio $C$. Doxorubicin-induced alopecia is associated with sebaceous gland differentiation. J Invest Dermatol 2006; 126: 711 - 720 
62 Braun KM, Niemann C, Jensen UB, Sundberg JP, Silva-Vargas V, Watt FM. Manipulation of stem cell proliferation and lineage commitment: Visualisation of label-retaining cells in wholemounts of mouse epidermis. Development 2003; 130: 5241 - 5255

63 Horsley V, O'Carroll D, Tooze R, Ohinata Y, Saitou M, Obukhanych T, Nussenzweig $M$, Tarakhovsky A, Fuchs E. Blimp1 defines a progenitor population that governs cellular input to the sebaceous gland. Cell 2006; 126: 597-609

64 Allen M, Grachtchouk M, Sheng H, Grachtchouk V, Wang A, Wei L, Liu J, Ramirez A, Metzger D, Chambon P, Jorcano J, Dlugosz A. Hedgehog sig- naling regulates sebaceous gland development. Am J Pathol 2003; 163: $2173-2178$

65 Takeda H, Lyle S, Lazar AJF, Zouboulis CC, Smyth I, Watt FM. Human sebaceous tumours harbour inactivating mutations in LEF1. Nat Med 2006; $12: 395-397$

66 Han G, Li AG, Liang YY, Owens P, He W, Lu S, Yoshimatsu Y, Wang D, Ten Dijke $P$, Lin $X$, Wang XJ. Smad7-induced beta-catenin degradation alters epidermal appendage development. Dev Cell BL 2006; 11: 301 312 